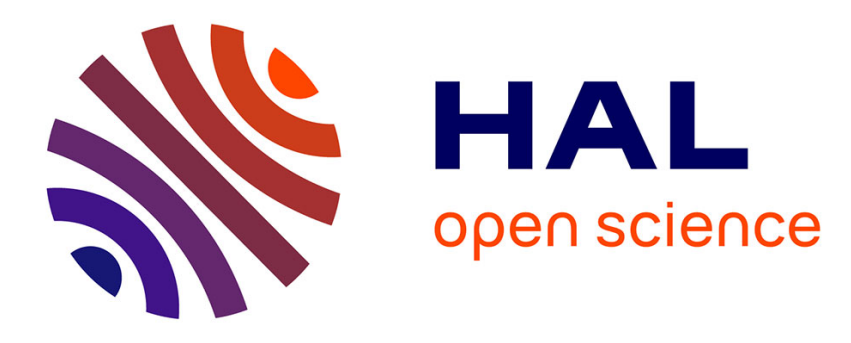

\title{
Photoconductivity in thin films of a-Ga40SeXTe60-X
}

\author{
A.S. Maan, D.R. Goyal, A. Kumar
}

\section{To cite this version:}

A.S. Maan, D.R. Goyal, A. Kumar. Photoconductivity in thin films of a-Ga40SeXTe60-X. Revue de Physique Appliquée, 1989, 24 (6), pp.613-617. 10.1051/rphysap:01989002406061300 . jpa-00246086

\section{HAL Id: jpa-00246086 https://hal.science/jpa-00246086}

Submitted on 1 Jan 1989

HAL is a multi-disciplinary open access archive for the deposit and dissemination of scientific research documents, whether they are published or not. The documents may come from teaching and research institutions in France or abroad, or from public or private research centers.
L'archive ouverte pluridisciplinaire HAL, est destinée au dépôt et à la diffusion de documents scientifiques de niveau recherche, publiés ou non, émanant des établissements d'enseignement et de recherche français ou étrangers, des laboratoires publics ou privés. 
Classification

Physics Abstracts

$72.20 \mathrm{~J}-72.40$

\title{
Photoconductivity in thin films of a- $\mathrm{Ga}_{40} \mathrm{Se}_{x} \mathrm{Te}_{60-x}$
}

\author{
A. S. Maan ( $\left.{ }^{1}\right)$, D. R. Goyal $\left({ }^{1}\right)$ and A. Kumar (2) \\ (1) Physics Department, Maharshi Dayanand University, Rohtak-124 001, India \\ (2) Department of Physics, Harcourt Butler Technological Institute, Kanpur-208 002, India
}

(Reçu le 12 septembre 1988, révisé le 16 février 1989, accepté le 7 mars 1989)

\begin{abstract}
Résumé. - Cet article présente des mesures de photoconductivité dans des films minces de verres $\mathrm{Ga}_{40} \mathrm{Se}_{x} \mathrm{Te}_{60-x}(x=20,30,40)$. La dépendance en température du photocourant à l'état stationnaire et du courant d'obscurité montrent que les photoconductivités correspondantes sont activées. L'intensité du photocourant montre une dépendance en loi de puissance en fonction de la radiation incidente. On a aussi effectué des mesures de photoconductivité transitoires sur tous les échantillons. On trouve que la décroissance du photocourant après coupure de l'irradiation est exponentielle dans tous les verres. La décroissance de $I_{\mathrm{ph}} / I_{\mathrm{d}}$ peut être expliquée par la croissance du nombre de défauts avec la concentration de Te.
\end{abstract}

Abstract. - Present communication reports on photoconductivity measurements in thin films of $\mathrm{Ga}_{40} \mathrm{Se}_{x} \mathrm{Te}_{60-x}$ glasses $(x=20,30,40)$. Temperature dependence of steady state photocurrent and dark current show that dark and steady state photoconductivity are activated processes. Intensity dependence of photocurrent reveals about power law dependence of photocurrent on incident radiation. Also incorporated are the transient photoconductivity measurements on all the samples. The decay of photocurrent after the cessation of illumination has been found to be exponential in all the glasses. The decrease in $I_{\mathrm{ph}} / I_{\mathrm{d}}$ can be explained in terms of the increasing no. of defect states with increasing Te content.

\section{Introduction.}

Due to manifold applications in different fields amorphous semiconductors and in particulars chalcogenide glasses are drawing a lot of attention. In order to optimize these materials for possible applications it is essential to understand the nature of recombination kinetics taking place in these materials. Chalcogenide glasses are generally characterized by a trap-limited carrier mobility, a Fermi energy in the center of the band gap, diamagnetic behaviour and an insensitivity to preparation conditions. Photoconductivity measurements are relevant from the application point of view as well as to understand the nature of localized states present in these materials.

Photoconductivity measurements have been carried out on a-semiconductors in bulk form or in thin film form [1-8] and a number of models [9-12] have been proposed to explain the results. The diverse nature of photoconducting properties in a-semiconductors is visible from presence of maxima with respect to temperature in some glasses [1-3] whereas its absence was reported in few others $[7,8]$. The intensity dependence of photocurrent on incident radiation has been reported to be linear in some cases $[2,4]$ whereas it is sq. root in others $[4,6,8]$. Decay of photocurrent, after the incident radiation is switched off has been reported as non exponential in some cases $[8,13,14]$, as a power law decay in a few others $[15,16]$ and also as a sum of exponential decays $[4,17,18]$ depending upon the nature of recombination process taking place in the material.

This communication reports about the photoconductivity studies in thin films of $\mathrm{Ga}_{40} \mathrm{Se}_{x} \mathrm{Te}_{60-x}$ $(x=20,30,40)$. Temperature dependence of steady state photoconductivity is studied at various levels of illumination in amorphous thin films of various compositions. Intensity dependence of photocurrent is studied at different temperatures in the range 310$370 \mathrm{~K}$. Also incorporated are transient photoconductivity measurements to analyse the nature of decay process taking place in present glasses.

In order to make comparison, the photoconduc- 
tivity results for one particular temperature or intensity are plotted in the figures. The results at other intensities or temperatures were found to be of the same nature. Further included are the temperature dependence of dark current.

\section{Experimental.}

Glasses of different compositions of $\mathrm{Ga}_{40} \mathrm{Se}_{x} \mathrm{Te}_{60-x}$ system were obtained in bulk form by usual quenching technique. Elements of 5 nines purity were sealed in evacuated quartz ampules in desired stichiometeric ratios. The ampules were then placed in an electric furnance with rocking arrangement and temperature was raised upto $1000^{\circ} \mathrm{C}$. The ampules were then kept at $\sim 1000^{\circ} \mathrm{C}$ for $10 \mathrm{~h}$ under continuous rocking and were then directly quenched into ice cooled water. The DSC measurements confirmed the glassy nature of the alloys and the glass transition temperature $\left(T_{\mathrm{g}}\right)$ values for the samples are given in table I.

Table I. - Glass transition temperature $\left(T_{\mathrm{g}}\right)$, conductivity $(\sigma)$, pre-exponential factor $\left(\sigma_{0}\right)$ and activation energy for different compositions.

\begin{tabular}{ccccc}
\hline Material & $T_{\mathrm{g}}\left({ }^{\circ} \mathrm{C}\right)$ & $\begin{array}{c}\text { Dark } \\
\text { conductivity } \\
(\sigma) \text { at } 325 \mathrm{~K}, \\
\Omega^{-1} \mathrm{~cm}^{-1}\end{array}$ & $\begin{array}{c}\sigma_{0} \\
\Omega^{-1} \mathrm{~cm}^{-1}\end{array}$ & $\Delta E$ \\
\hline $\mathrm{Ga}_{40} \mathrm{Se}_{40} \mathrm{Te}_{20}$ & 181 & $8.46 \times 10^{-7}$ & 0.90 & $0.38 \mathrm{eV}$ \\
$\mathrm{Ga}_{40} \mathrm{Se}_{30} \mathrm{Te}_{30}$ & 161 & $1.26 \times 10^{-6}$ & 0.042 & $0.29 \mathrm{eV}$ \\
$\mathrm{Ga}_{40} \mathrm{Se}_{20} \mathrm{Te}_{40}$ & 153 & $10.05 \times 10^{-6}$ & $2.47 \times 10^{-3}$ & $0.22 \mathrm{eV}$ \\
\hline
\end{tabular}

Thin films of different glasses were obtained from the bulk material by vacuum evaporation in a standard coating unit. Well degassed glass plates with high purity indium deposited onto them by vacuum evaporation were used as a substrates for depositing amorphous thin films. The coplanar geometry (length $\sim 2 \mathrm{~cm}$ and electrode gap $\sim 0.2 \mathrm{~mm}$ ) so obtained was used for photoconductivity measurements. For the sake of comparison of results, the thickness of the amorphous films and other deposition parameters were kept about constant.

Thin film samples were annealed in vacuum at $373 \mathrm{~K}$ for about two hours. The incident radiation used for photoconductivity measurements was obtained from a $200 \mathrm{~W}$ tungsten lamp. The photoconductivity measurements were carried out under a vacuum of $10^{-3}$ Torr. The effect of monochromatic radiations obtained by using interference filters in the range $420-660 \mathrm{~nm}$ was observed and the results were found to be of the same nature as with the white light. The reported results are with white light owing to better photon flux. Proper care was taken to avoid the thermal effects of incident radiation.

The voltage applied across the samples was $1.5 \mathrm{~V}$ obtained by a dry cell. The samples were however found to be ohmic upto $30 \mathrm{~V}$ in the absence as well as in the presence of light. The current measurements were accurate upto $1 \mathrm{pA}$. Temperature measurements were done by a calibrated copperconstantan thermocouple attached to a $31 / 2$ digital temperature indicator and were accurate upto $0.1^{\circ} \mathrm{C}$.

\section{Results and discussion.}

Temperature dependence of dark current of different compositions of $\mathrm{Ga}_{40} \mathrm{Se}_{x} \mathrm{Te}_{60-x}$ system was observed in the temperature range $310-373 \mathrm{~K}$. Figure 1 represents the values of $I_{\mathrm{d}}$ (dark current) plotted logarithmically against $1000 / T$ for thin films of the system with $x=20,30$ and $40 \%$. In $I_{\mathrm{d}} v s$. $1000 / T$ plots are straight lines for all the samples and show that dark conductivity in these samples is an activated process having a single activation energy $(\Delta E)$ in the observed temperature range. The conductivity of the samples decreases as Se content increases. Similar behaviour in the dark conductivity has been reported in As-Se-Te glasses [19] with the variation of $\mathrm{Se}: \mathrm{Te}$ ratio though the preexponential factor $\sigma_{0}$ shows different behaviour in the two systems. Values of $\sigma_{0}$ and $\Delta E$ were computed and are given in table $\mathrm{I}$. It is found that in present samples $\sigma_{0}$ decreases with increase in Te percentage.

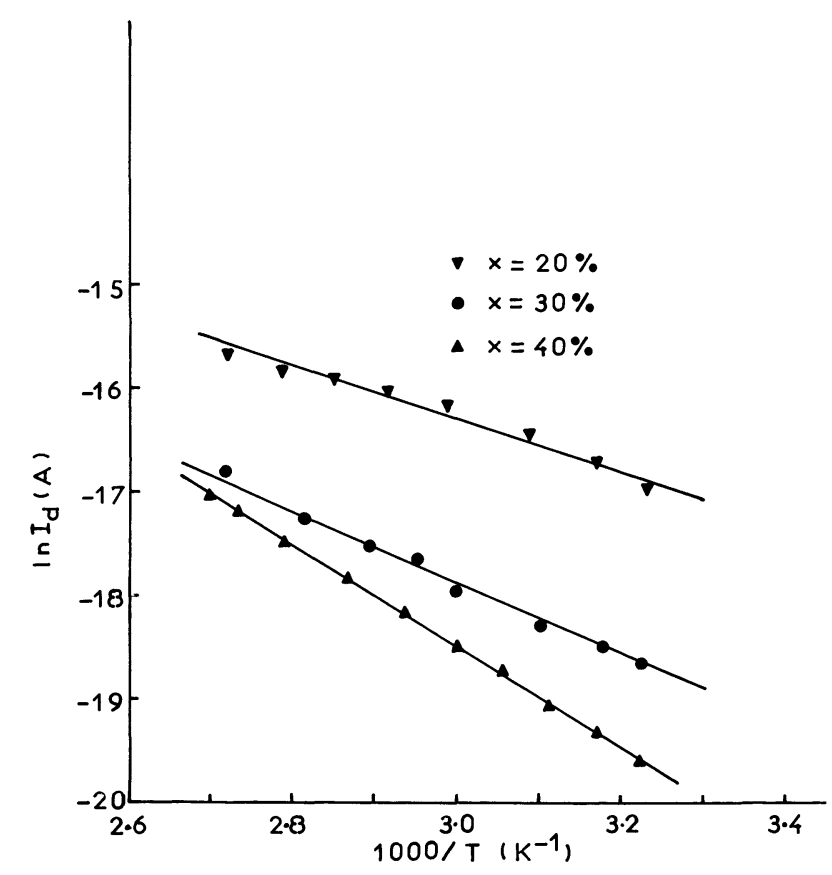

Fig. 1. $-\ln I_{\mathrm{d}}$ (dark current) against $1000 / T$ for $\mathrm{Ga}_{40} \mathrm{Se}_{x} \mathrm{Te}_{60-x}$ system $(x=20,30,40)$. 
In chalcogenide glasses $\sigma_{0}$ in the range $10^{3}-10^{4} \Omega^{-1} \mathrm{~cm}^{-1}$ indicates the conduction in extended states, whereas a lower value of $\sigma_{0}$ is an indication of a wide range of localized states [20]. From the results of table $I$ it seems that increasing Te content leads to an increase in the density of localized states.

The temperature dependence of photocurrent was observed at various illumination intensities in all samples. Figure 2 represents the variation of the photocurrent $\ln \left(I_{\mathrm{ph}}\right)$ against $1000 / T$ at three different illumination intensities for $\mathrm{Ga}_{40} \mathrm{Se}_{30} \mathrm{Se}_{30}$ glass. Figure 2 shows that photoconductivity is an activated process and that the activation energy for photoconduction is almost the same for the three levels of illumination.

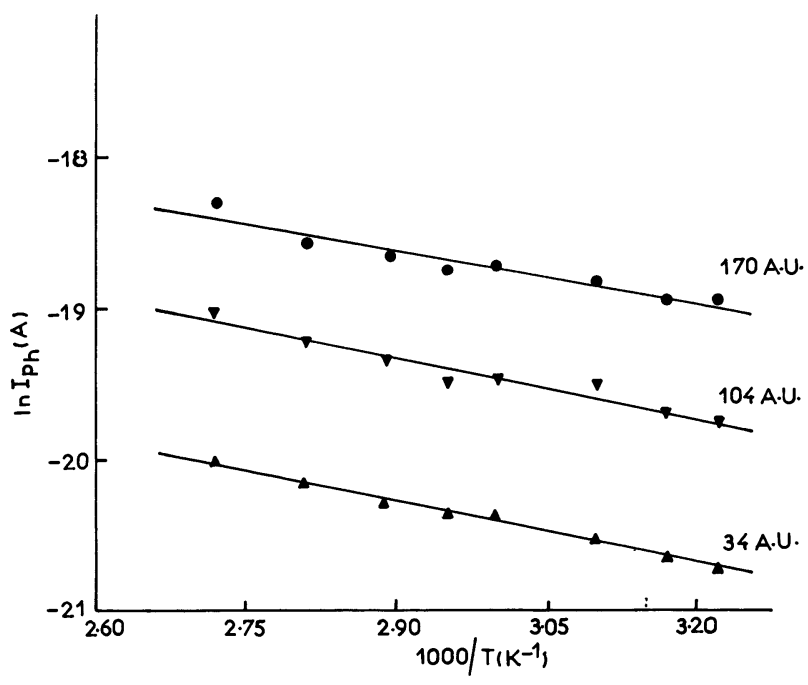

Fig. 2. $-\ln I_{\text {ph }}$ against $1000 / T$ for $\mathrm{Ga}_{40} \mathrm{Se}_{30} \mathrm{Te}_{30}$ glass at three levels of illumination.

Photocurrent does not reach a maximum with temperature in the explored temperature range in any of the samples. Absence of maxima in photoconductivity has been predicted in amorphous semiconductors [20] if photogenerated carrier densities are less than in the dark $\left(I_{\mathrm{ph}}<I_{\mathrm{d}}\right)$ at room temperature. Absence of maxima w.r.t. temperature for $x=20$, and $x=30$ samples is in agreement with the above prediction as $I_{\mathrm{ph}}<I_{\mathrm{d}}$ in these samples. Similar absence of maximum has been reported by Shiah and Bube [21] in a number of glassy alloys. Though $I_{\mathrm{ph}}>I_{\mathrm{d}}$ at room temperature for $x=40$ sample, yet no maximum could be observed in this sample. A behaviour similar to that of $\mathrm{Ga}_{40} \mathrm{Se}_{40} \mathrm{Te}_{20}$ has been reported for a number of glasses $[8,21,22]$ where photocurrent is greater than dark current at room temperature. Activation energy for photoconduction was computed for different $x$ values and are given in table II.
Table II. - Various photoconductivity parameters for different compositions.

\begin{tabular}{ccccc}
\hline Material & $\begin{array}{c}\gamma \\
\text { at } 310 \mathrm{~K}\end{array}$ & $\begin{array}{c}I_{\mathrm{ph}} / I_{\mathrm{d}} \\
\text { at } 310 \mathrm{~K}\end{array}$ & $\Delta E_{\mathrm{ph}}$ & $\begin{array}{c}\tau \text { at } 310 \mathrm{~K} \\
(\mathrm{~s})\end{array}$ \\
\hline $\mathrm{Ga}_{40} \mathrm{Se}_{40} \mathrm{Te}_{20}$ & 0.75 & 1.42 & $0.12 \mathrm{eV}$ & 69 \\
$\mathrm{Ga}_{40} \mathrm{Se}_{30} \mathrm{Te}_{30}$ & 0.96 & 0.88 & $0.11 \mathrm{eV}$ & 71 \\
$\mathrm{Ga}_{40} \mathrm{Se}_{20} \mathrm{Te}_{40}$ & 1.00 & 0.23 & $0.18 \mathrm{eV}$ & 65 \\
\hline
\end{tabular}

Intensity dependence of photoconductivity has been studied for all the samples. Values of $\ln I_{\mathrm{ph}}$ against $\ln F$ (A.U.) are plotted in figure 3 for different samples at $310 \mathrm{~K}$. Figure 3 shows that photoconductivity follows power law on incident radiation $\left(\sigma_{\mathrm{ph}} \propto F^{\gamma}\right)$. Values of $\gamma$ were obtained from the slope of the curves in figure 3 and are inserted in table II. Value of $\gamma$ seems to increase as Te content is increased in present system. The value of $\gamma$ (Tab. II) for $x=20,30$ is nearly one $(\sim 1.0)$ indicating that the recombination is monomolecular.

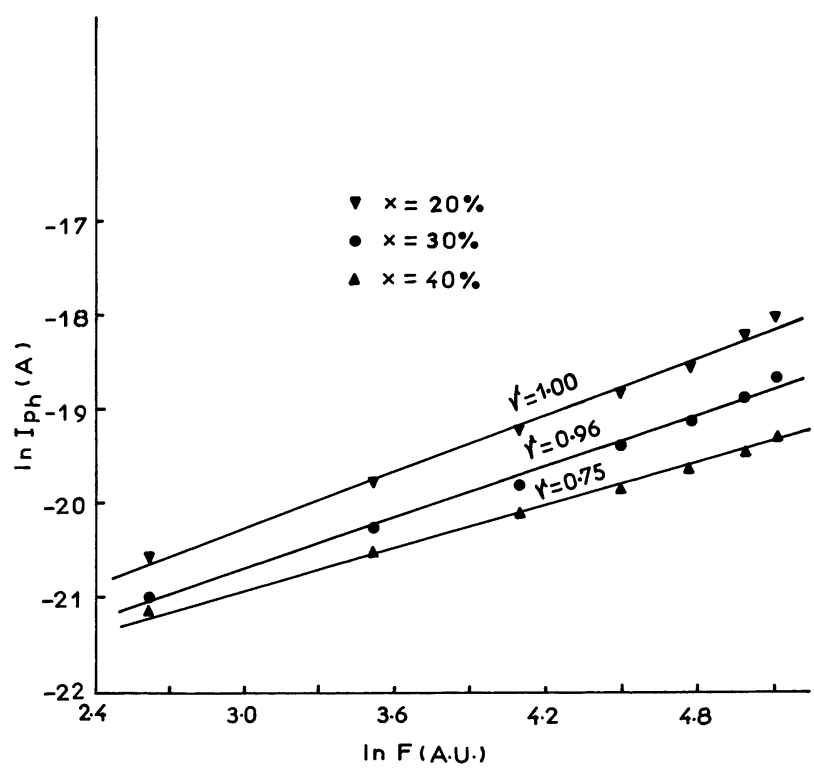

Fig. 3. $-\ln I_{\mathrm{ph}}$ against $\ln F$ (A.U.) for different $x$ values in the $\mathrm{Ga}_{40} \mathrm{Se}_{x} \mathrm{Te}_{60-x}$ system.

For the sample with $x=40$, the $\gamma$ has dropped to 0.75 . According to Rose [23] the value of $\gamma$ between 0.5 and 1.0 can be justified by assuming the existence of continuous distribution of states in the band gap and the resulting recombination will be bimolecular. Arene and Baixeras [24] and others [17, 25] have observed the values of $\gamma$ lying between 0.5 and 1.0 in different amorphous materials which has been attributed to the distribution of localized states in the energy gap. This behaviour is also quite understandable in the light of the relative values of photocurrent and dark current. For $x=40$, the photocurrent is 
larger than the dark current and thus the recombination has to be bimolecular [20] whereas, for $x=20,30$ photogenerated carriers are less than dark carriers $\left(I_{\mathrm{ph}}<I_{\mathrm{d}}\right.$, see Tab. II) and recombine into the pool of thermally produced recombination centres and thus monomolecular recombination takes place [20].

$I_{\mathrm{ph}} / I_{\mathrm{d}}$ for different $x$ values calculated at $310 \mathrm{~K}$ and given in table II show that $I_{\mathrm{ph}} / I_{\mathrm{d}}$ decreases with increasing Te content. This parameter depends on the life time of photogenerated carriers, which in turn depends upon the density of localized states in the energy gap. Higher density of localised states leads to lower value of carrier life time resulting in low value of $I_{\mathrm{ph}} / I_{\mathrm{d}}$ [25]. A similar effect of $\mathrm{Te}$ content on the localized states concentration has been observed by us during dielectric measurements of these samples reported elsewhere [26].

Transient photoconductivity measurements were made on all the samples. Rise and decay of photocurrent was observed by using incident radiation of fixed intensity (170 A.U.) and is found is to be quite slow in all the samples. In a material with traps in the energy gap, the recombination time of carriers is same as carrier life time in the case when free carrier density is much more than the trapped carrier density [27]. If the density of free carriers is much less than the trapped carriers, the resulting recombination is effectively dominated by the rate of trap emptying and is much larger than the carrier life time, resulting in a slow decay. A comparison of the results in figure 4 indicates that the rise and decay of photocurrent for $x=40$ sample is faster as compared to other $x$ values.

Figure 4 shows that there is an increment in the value of current in all the samples even after a long time when the incident light was cut off. It is believed that this increment may not be simply due to carriers trapped in localized states [28]. For simplification of the decay analysis, persistent current was subtracted from the observed values and the corrected values of $I_{\mathrm{ph}}$ (decay) are plotted logarithmically against time $(t)$ for different $x$ values in figure 5.

In disordered materials presence of traps plays an important role in the photoconductivity through trap filling and emptying processes. The traps which are filled during excitation will empty, at a rate depending upon their cross-section and ionization energy. If the retrapping of carriers freed from traps can be neglected then an exponential decay is expected [27] as guided by the relation $p \sim p_{0} \exp (-t / \tau)$ where $\tau$ is the decay time constant. Results in figure 5 show that decay of photocurrent is exponential in all the samples except near the onset of transients where recombination is faster and this fast component goes on increasing with increasing $x$ values.

Using the plots in figure 5 , decay time constant

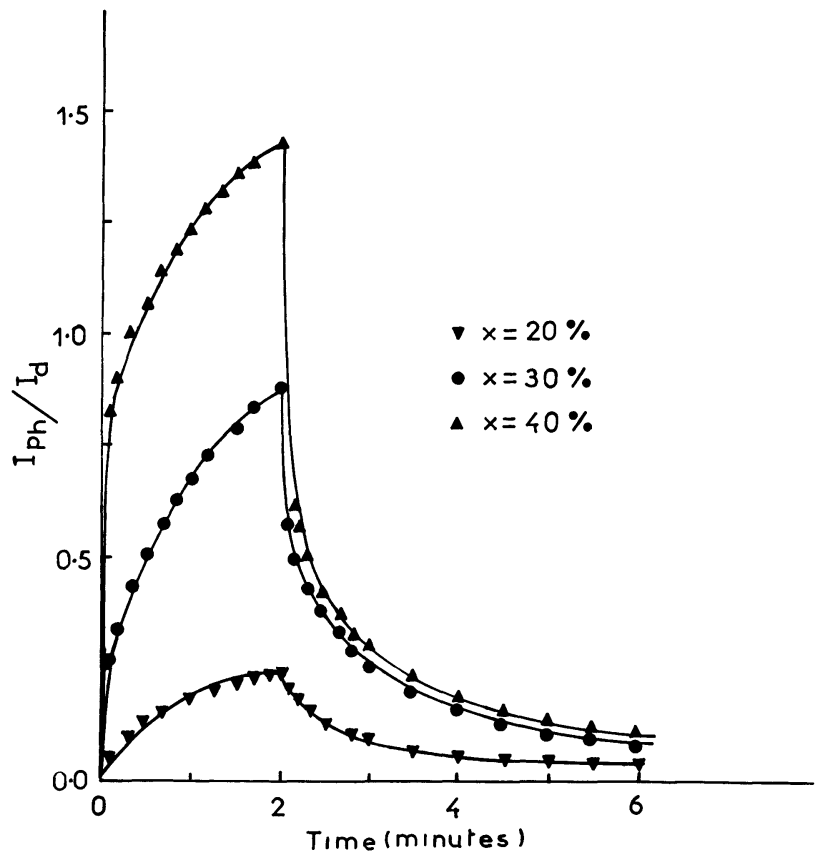

Fig. 4. - Rise and decay of photocurrent (expressed in $\left.I_{\mathrm{ph}} / I_{\mathrm{d}}\right)$ with time $(t)$ for different $x$ values at $310 \mathrm{~K}$ and at intensity 170 A.U.

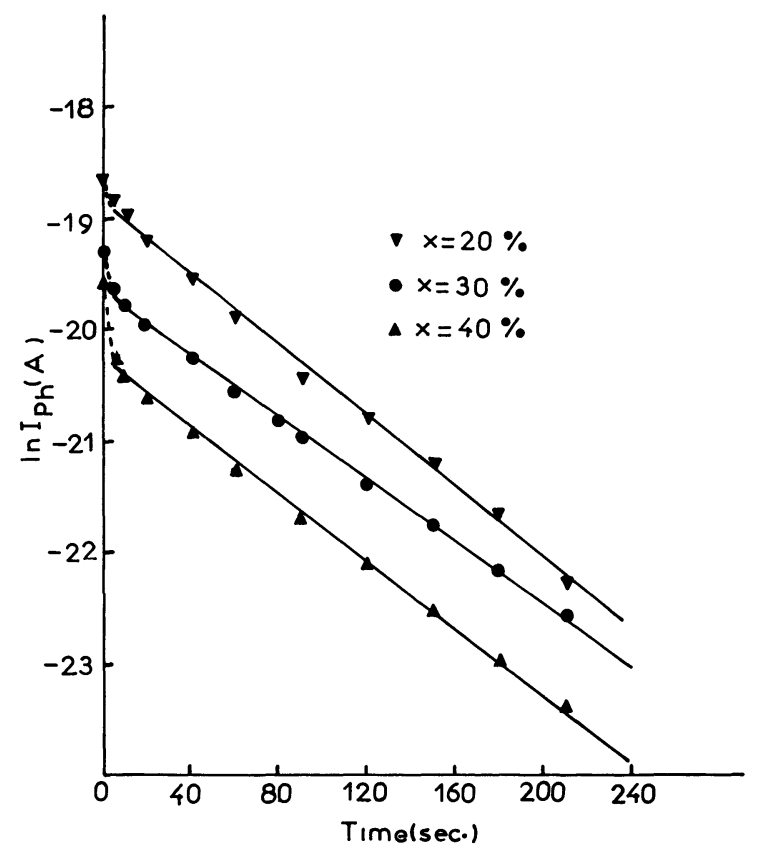

Fig. 5. $-\ln I_{\mathrm{ph}}$ (decay) against time $(t)$ for different $x$ values.

$(\tau)$ was calculated for different $x$ values and are given in table II. Value of decay time constant $(\tau)$ does not show a regular dependence on $x$ values. Similar behaviour has been observed in the macroscopic relaxation time values $\left(\tau_{0}\right)$ obtained during the electric measurements [26].

To conclude, photoconductivity with respect to 
temperature is an activated process in all the samples. There is power law dependence of photocurrent $\left(I_{\mathrm{ph}} \propto F^{\gamma}\right)$ on incident radiation. $I_{\mathrm{ph}} / I_{\mathrm{d}}$ values calculated for different samples increase with increasing $x$ values. This behaviour is consistent with the dark conductivity observations which indicate the increasing number of defect states with increasing $\mathrm{Te} \%$. Similar effect of increasing $\mathrm{Te} \%$ in the present system has been observed by us during the dielectric measurements [26].

\section{References}

[1] Bube R. H., Mahan H. E., Shiah R. T. S. and VAN Der Plas H. A., Appl. Phys. Lett. 25 (1974) 419.

[2] FAgen E. A. and Fritzsche H., J. Non-Cryst. Solids 4 (1970) 480.

[3] Tripathi S. K. and Kumar A., J. Electron. Mater. 17 (1988) 45.

[4] Shimakawa K., Yoshida A. and Arizumi T., $J$. Non-Cryst. Solids 16 (1974) 258.

[5] Chamberlain J. M. and Moseley A. J., Jpn J. Appl. Phys. 21 (1982) 13.

[6] Moseley A. J. and Chamberlain J. M., Philos. Mag. B 43 (1981) 1065.

[7] Igalson M. and Trykozoko R., Solid State Commun. 40 (1981) 99.

[8] MaAn A. S., Sharma A. K., Goyal D. R. and Kumar A., J. Non-Cryst. Solids 104 (1988) 273.

[9] ARkhipov V. I., Sov. Phys.-Semicond. U.S.A. 16 (1982) 1336.

[10] Weiser K., J. Non-Cryst. Solids 8-10 (1972) 922.

[11] Street R. A., Phys. Rev. B 17 (1978) 3984.

[12] MAIN C. and OWEN A. E., Electronic and Structural Properties of a-semiconductors (Academic press London and New York) 1973.

[13] Funs W. and Meyer D., Phys. Status Solidi A 24 (1974) 275.

[14] Goel S. and Kumar A., Thin Solid Films 151 (1987) 307.
[15] Orenstein J., Kastner M. and Monroe D., J. Non-Cryst. Solids 35-36 (1980) 951.

[16] Khan B. A., Kastner M. A. and Adler D., Solid State Commun. 45 (1983) 187.

[17] MaAn A. S., Goyal D. R. and Kumar A., Communicated to J. Non-Cryst. Solids.

[18] Haynes J. R. and Hornbeck J. A., Phys. Rev. 100 (1955) 606.

[19] Mahadevan S., Giridhar A. and RaO K. J., J. Phys. C 10 (1977) 4499.

[20] MotT N. F. and DAVis E. A., Electronic processes in Non Crystalline Materials (Clarendon Press Oxford) 1979.

[21] Shiah R. T. S. and Bube R. H., J. Appl. Phys. 47 (1976) 2005.

[22] Taylor G. W. and Simmons J. G., J. Phys. C 7 (1974) 3051.

[23] Rose A., Concept in Photoconductivity (Interscience, New York) 1963.

[24] Arene E. and Baixeras J., Phys. Rev. B 30 (1984) 2016.

[25] Mathur R. and Kumar A., Solid State Commun. 61 (1987) 785.

[26] MaAn A. S., Goyal D. R. and Kumar A., to be published.

[27] BubE R. H., Photoconductivity of Solids (John Wiley and Sons Inc.) 1979.

[28] Igalson M., Solid State Commun. 44 (1982) 247. 